\title{
Severe Vision Impairment and Blindness in Hospitalized Patients: A Nationwide Study
}

Che Harris ( $\square$ charri21@jhmi.edu )

Johns Hopkins University School of Medicine https://orcid.org/0000-0002-8010-9449

Scott M Wright

Johns Hopkins University School of Medicine

Research article

Keywords: impairment, blindness, SVI/B, Nationwide Inpatient Sample,

Posted Date: December 4th, 2020

DOI: https://doi.org/10.21203/rs.3.rs-66211/v2

License: (c) (i) This work is licensed under a Creative Commons Attribution 4.0 International License. Read Full License 


\section{Abstract}

Background: Outcomes among hospitalized patients with severe vision impairment or blindness have not been extensively explored. This study sought to determine clinical and resource utilization outcomes in patients with severe vision impairment/blindness (SVI/B). Because the obesity epidemic is also on the rise and underrecognized in hospital settings, we also sought to understand its impact among patients with SVI/B.

Methods: We conducted a retrospective study using the National Inpatient Sample for the year 2017; hospitalized adults with and without SVI/B were compared. In addition, for all patients with SVI/B, we compared those with and without obesity. Multiple logistic regression and linear analysis were used to evaluate mortality, disposition, length of stay, and hospital charges. We adjusted for age, sex, race, comorbidities, insurance, and income.

Results: $30,420,907$ adults were hospitalized, of whom 37,200 had SVI/B. Patients with SVI/B were older (mean age \pm SEM: $66.4 \pm 0.24$ vs. $57.9 \pm 0.09$ years, $p<0.01)$, less likely to be female ( $50 \%$ vs $57.7 \%, p<0.01)$, more frequently insured by Medicare $(75.7 \% v s 49.2 \%, p<0.01)$, and had more comorbidities (Charlson comorbidity score $\geq 3: 53.2 \%$ vs $27.8 \%, \mathrm{p}<0.01)$. Patients with SVI/B had a higher in-hospital mortality rate ( $3.9 \%$ vs $2.2 \% ; p<0.01$ ), and they were less likely discharged home (adjusted Odds Ratio $\{a O R\}=0.54$, [Confidence Interval $(\mathrm{Cl}) 0.51-0.58$ ]; $p<0.01)$ compared to those without visual impairment. Hospital charges were not significantly different (adjusted Mean Difference $\{\mathrm{aMD}\}=\$ 247 \mathrm{Cl}[-\$ 2,474-2,929]$; $\mathrm{p}=0.85$ ) but length of stay was longer $(\mathrm{aMD}=0.5$ days $\mathrm{Cl}[0.3-0.7] ; p<0.01)$ for those with $\mathrm{SVI} / \mathrm{B}$. Visually impaired patients who were also obese had higher total hospital charges compared to those without obesity (mean difference: $\$ 9,821$ [Cl $\$ 1,375-\$ 18,268] ; p=0.02$ ).

Conclusion: Patients admitted to American hospitals in 2017 who had severe vision impairment or blindness had worse clinical outcomes and greater resources utilization. Hospital-based healthcare professionals should recognize that because those with visual impairment are at risk for worse outcomes, extra attention to detail may be warranted to minimize the propagation of such disparity.

\section{Background}

It is estimated that between $3.4-21$ million adults in the United States are visually impaired or blind, and up to 80 million have eye diseases that may ultimately lead to blindness (1). Furthermore, the annual economic impact of blindness is estimated to be over 35 billion dollars (2). As the population ages, the number of Americans with blindness is expected to double by the year 2030 (1). As such, an increasing number of patients with blindness will be hospitalized; hospital providers of all disciplines will invariably become progressively more involved in their care. Unfortunately, few studies have sought to screen for and consider poor vision during hospitalizations when visual disturbances are not related to the chief reason for admission (3). While it has been established that vision impairment is associated with inpatient complications outcomes, such as falls and delirium $(4,5)$, no US based national study has investigated in-hospital mortality in patients with severe vision impairment or blindness (SVI/B). Morse determined that older Medicare recipients with severe vision loss utilized more healthcare resources compared to those without this disability (6). However, the impact on a broader age range of patients with SVI/B has not been studied on a national level. We used the National Inpatient Sample (NIS) database for the year 2017, and hypothesized that hospitalized patients with SVI/B would have higher in-hospital mortality, less likely to be discharged home following hospitalization, have longer hospital stays, and greater hospital charges compared to those who were non-visually impaired. Given the worsening obesity epidemic in United States and the uncertain effect it was having on patients admitted who had $\mathrm{SVI} / \mathrm{B}$, a subgroup analysis was also carried out to investigate the additive impact of obesity on these same outcome variables.

\section{Methods}

\section{Setting / Database}

This study used the 2017 NIS database, available through the Agency for Healthcare Research and Quality provided by the Healthcare Cost and Utilization Project (7). NIS is the largest United States based publicly available all-payer inpatient health care database (7). It approximates a $20 \%$ stratified sample of US hospital discharges from 46 participating states. The NIS has data for more than 7 million unweighted hospital stays per year. When weighted to represent all admissions, it estimates more than 35 million hospitalizations annually, and represents about $95 \%$ of US hospitalizations. Strata include hospital size/volume, teaching status, geographic region, and hospital ownership. Data from 2017 NIS uses the International Classification of Diseases, 10th Revision, Clinical Modification (ICD-10-CM) coding system for all discharge diagnoses.

\section{Study Population, Patient and Hospital Characteristics, and Outcomes}

All patients $\geq 18$ years of age were included in the sample. We then identified selected patients with bilateral severe visual impairment or bilateral blindness as described by their ICD-10 CM codes (eye category 2 through 5 for either eye): https://www.icd10monitor.com/looking-at-new-icd-10cm-codes-for-blindness (updated September 27th 2017). In addition, ICD-10 code H54.0 was also used for bilateral blindness. Supplementary Table A with ICD-10 codes provides specific descriptions of categories for each level of SVI/B. Severe blindness has been defined as individuals with visual acuity worse than $6 / 60$, and blindness as those with visual acuity worse than $3 / 60(8)$. 
ICD-10 codes used for our subgroup analysis to study the impact of obesity as a secondary diagnosis on patients with SVL/B was also retrieved (See Supplementary A table for ICD-10 codes and corresponding diagnoses). For adults, obesity is defined as having a Body Mass Index (BMI) of 30 or greater (9). BMI is calculated by taking the individual's weight in kilograms and dividing it by their height in meters squared.

Data was collected and adjusted for select patient and hospital characteristics including age, gender (male and female only), race (White, Black, Hispanic, Asian or Pacific Islander), insurance (Medicare, Medicaid, Private Insurance, Uninsured), median household income (1. \$1-\$38,999 2. $\$ 39,000-\$ 47,999$ 3. $\$ 48,000-\$ 62,9994$. $\$ 63,000$ or more), based on home zip code, and the Charlson comorbidity index (CCl: score $0=$ no comorbidities score $1=$ low comorbidity burden, score 2 = moderate comorbidity burden, and score 3 or greater = high comorbidity burden). The CCI has been used extensively in clinical research; it is commonly used to assess mortality risk and it is supported by extensive validity evidence (10). Higher scores have been associated with mortality or greater healthcare resource use (11).

The primary outcome was mortality during hospitalization; secondary outcomes were total hospital charges, length of stay (LOS), and disposition after hospitalization. Disposition indicates the discharge location or where patients go after hospitalization. This is most often home, but not infrequently can be elsewhere including venues such as other hospitals, inpatient hospice, inpatient rehabilitation facilities, and nursing homes (https://www.hcup-us.ahrq.gov/db/vars/sedddistnote.jsp?var=dispuniform).

Our Institutional Review Board designated this work as being exempt from detailed review (IRB review number: 00257552).

\section{Statistical analyses}

Comparisons were examined between patients with SVI/B and the general population without visual impairments using Pearson's $\chi^{2}$ tests and oneway analysis of variance to test categorical and continuous variables. Analyses were also carried out within the SVI/B patient cohort assessing those with and without obesity. The primary and secondary outcomes were adjusted for all of the patient demographics and hospital characteristics shown in Table 1, as well as the $\mathrm{CCl}$ and select specific comorbidities described in Table 2.

Adjusted odds ratios [aOR] and adjusted mean differences [aMD] from multivariate logistic and linear regression analyses were obtained. Binary outcomes under logistic regression analyses (in-hospital mortality and discharge disposition) were studied. Linear regression was used to study continuous outcome variables (including total hospital charges and LOS). Stata 15.0 statistical software (Stata Corp, College Station, TX) was used and permitted us to account for design complexity (stratification, weighting, and clustering) (7). The p-values for this study were 2 sided and type I error significance level was set at 0.05 .

\section{Results}

In $2017,35,769,613$ adults $\geq 18$ years of age were hospitalized in the United States. From this group, 37,200 patients were severely visually impaired or blind (see Figure). Demographic data is shown in Table 1. SVI/B patients were older (mean age \pm SEM: $66.4 \pm 0.24$ vs. $57.9 \pm 0.09$ years, $p<0.01$ ), less likely to be female ( $50 \%$ vs $57.7 \%, p<0.01)$, and a higher proportion were insured by Medicare $(75.7 \%$ vs $49.2 \%, p<0.01)$. Table 2 displays that patients with SVI/B had a greater comorbidity burden (Charlson comorbidity score $\geq 3: 53.2 \%$ vs $27.8 \%$, $p<0.01$ ), as well as higher rates of vascular and pulmonary comorbidities.

\section{Patient Clinical and Resource Utilization Outcomes}

Table 3 shows that patients with SVI/B had higher rates of mortality compared to the general population of hospitalized adults (3.9\% vs $2.2 \%$; $\mathrm{p}<0.01)$. This finding held after adjusting for potential confounders where in-hospital mortality for patients with SVI/B remained higher compared to those without vision impairment (adjusted Odds Ratio $(\mathrm{aOR})=1.2$, [Confidence Interval $(\mathrm{Cl})$ 1.0-1.4]; $\mathrm{p}=0.01$ ). Patients with SVI/B were also less likely discharged home (adjusted Odds Ratio $\{\mathrm{aOR}\}=0.54$, [Confidence Interval $(\mathrm{Cl}) 0.51-0.58$ ]; $\mathrm{p}<0.01$ ). Total hospital charges were not significantly different (adjusted Mean Difference $\{\mathrm{aMD}\}=\$ 247 \mathrm{Cl}[-\$ 2,474-2,929] ; \mathrm{p}=0.85$ ) between groups, but LOS was longer (aMD=0.5 days CI [0.3-0.7]; $p<0.01)$ for those with SVI/B.

\section{Subgroup analysis focused on obesity}

Among patients with SVI/B, 32,201 (86.5\%) were not obese and 4,999 (13.5\%) were classified as obese. Patients with obesity were younger (mean age \pm SEM: $61.5 \pm 0.53$ vs. $67.2 \pm 0.27$ years, $p<0.01)$ and a higher proportion were female $(58.8 \%$ vs $48.6 \%, p<0.01)$. Patients with obesity had higher comorbidities (Charlson comorbidity scores $\geq 3: 65.0 \%$ vs $51.8 \%, p<0.01$ ). Table 4 shows that obese status was not associated with an altered LOS, odds of mortality, or likelihood of being discharged to home. However, SVI/B patients with obesity had higher total hospital charges compared to those without obesity (mean difference: $\$ 9,821$ [CI $\$ 1,375-\$ 18,268] ; p=0.02$ ).

\section{Discussion}

Millions of Americans have severe visual impairment or are blind. As rates continue to climb with the aging of the population, inpatient providers will encounter more patients with this disability and they will be expected to effectively manage this vulnerable population. This study shows that 
compared to those who are not visually impaired, patients with SVI/B who are hospitalized have higher mortality rates, longer LOS, and are less likely to be discharged to home following the admission. Moreover, among patients with SVI/B, those who were obese had higher total hospital charges than their non-obese counterparts, and as the obesity epidemic continues to soar, more patients with SVI/B who are obese can be expected to be hospitalized

A 2013 study from Western Australia discovered that legally blind hospitalized adults had a seven times higher mortality rate compared to patients with normal vision (12). This was carried out using a regional registry; the analysis reviewed over 12,000 hospitalizations of blind adults between study years 1999 and 2010. In a longitudinal study from 2002-2013 using the Korean National Health Insurance database, Choi also found that those with blindness (>1200 individuals) also had a higher mortality than patients with normal sight (13). This association held in distinct analyses assessing both older (> 60 years of age) and younger (< 60 years) patients (13). In 2013, the World Health Organization (WHO) launched a global action plan for universal eye health with specific guidance for caring for those with SVI/B (14). These efforts were intended to heighten awareness and escalate the reporting of vision loss in hopes of modifying clinical practice. The current study provides more recent results compared to those from Australia and Korea, while substantiating their findings within a larger cohort. Further, the associations noted among patients hospitalized in the US illustrate that the WHO's concerns about worse healthcare outcomes among those who are blind are still justified. Though the specific cause of the higher mortality among SVI/B patients cannot be determined in this observational study, plausible possibilities include a higher unmeasured comorbidity burden and presenting to hospital later in the course of illness with more advanced disease.

To explore in-hospital resource utilization, Morse studied two claims databases - Medicare database and Clinformatics DataMart; their objective was to compare the care of older hospitalized patients with and without vision loss (6). The study found that patients with severe vision loss had longer LOS, more readmissions, and higher hospital costs compared to patients without vision loss. Though our study also found that patients with SVI/B had longer LOS, there were not significantly higher hospital charges compared to those without this disability. The differences in the results might be explained by the fact that our patient population was broader, including younger hospitalized adults. Also, if the longer LOS was attributable to time spent on education and coordination of care, the lack of variance in charges accrued over the protracted time span may be linked to Taheri's observations that LOS attributable to the last portion of the hospitalization does not significantly contribute to hospital costs (15). For these very reasons, LOS is not always correlated with hospital costs (16). Given that a significantly higher number of SVI/B patients were discharge to facilities rather than to their homes, it may be reasonable to presume that they did not amass high charges while awaiting placement. Though we cannot be certain why SVI/B patients were less likely to be discharged home, it is not unreasonable to speculate that difficulty complying with post-discharge plans and therapies, either real or imagined by the inpatient care team, may have contributed to the decision. Continuation of some therapies after discharge (particularly those involving injections or infusions) may be especially difficult among those with SVI/B; places with some supervision (e.g. rehabilitation, nursing home...) may have been deemed to be safer and associated with a lower risk of readmission than going home - especially for those living alone or without reliable caregivers (17). While homecare services can be excellent, patients with visual impairments or other disabilities may need more support after discharge necessitating some time in subacute facilities before transitioning back to their homes.

The cohort of hospitalized SVI/B patients who were obese had significantly higher average charges; this result is similar to other studies that have examined the impact of obesity among those who are hospitalized (18). The prevalence of obesity may be higher among visually impaired people compared to the general population and other disabled populations $(19,20)$. The reasons for this may be related to both challenges with exercising or burning calories, and barriers with securing or preparing a healthful diet. These details may result in hospital-based providers caring for increasing proportions of SVI/B patients who are also obese. Nutritional counseling of these patients while they are in the hospital may be a reasonable intervention.

Several limitations of this study should be considered. First, the NIS is an administrative database wherein data is highly dependent on coding imputations. It is possible that under-coding for SVI/B and obesity may have occurred. Second, the NIS lacks detailed lab data or imaging results, and medications cannot be examined. Thus, an in-depth investigation into the details of our findings was not feasible. Third, special circumstances that might have influenced diagnostic or treatment decisions, such as social factors and patients' preferences, cannot be determined from administrative databases. Lastly, in observational studies there may be unmeasured and unknown confounders that influence outcomes. Observed associations suggest relationships between variables but do not prove causality.

\section{Conclusions}

Patients with severe visual impairment or blindness have worse clinical outcomes and higher resources utilization when hospitalized compared to those without this disability. Hospital-based healthcare providers should recognize this vulnerability and consider how to optimally care for and serve this group of patients.

\section{Abbreviations}

SVI/B: Severe Vision Impairment/Blindness 
NIS: National Inpatient Sample

SEM: Standard Estimated Mean

aOR: adjusted Odds Ratio

aMD: adjusted Mean Difference

Cl: Confidence Interval

ICD-10-CM: International Classification of Diseases, 10th Revision, Clinical Modification

US: United States

TX: Texas

LOS: Length of Stay

WHO: World Health Organization

\section{Declarations}

\section{Ethics declarations}

The study was not submitted for research ethics approval as the activities described were conducted as part of the National Inpatient Sample (NIS), which is part of the family of databases and software tools developed for the Healthcare Cost and Utilization Project (HCUP) and uses deidentified data collected from hospitalized patients. The study activities obtained from NIS are exempt from the Johns Hopkins' Institutional Review Board and do not require informed consent. For additional details, please refer to the following website links: https://www.hopkinsmedicine.org/institutional_review_board/guidelines_policies/guidelines/exempt_research.html;https://www.ecfr.gov/cgi$\mathrm{bin} /$ retrieveECFR?gp=\&SID=83cd09e1c0f5c6937cd9d7513160fc3f\&pitd=20180719\&n=pt45.1.46\&r=PART\&ty=HTML\#se45.1.46_1104.

\section{Consent for Publication}

Not applicable. All data using the National Inpatient Sample is de-identified.

\section{Availability of data and materials}

Researchers should readily be able to purchase the same databases we did to conduct research here: https://www.distributor.hcupus.ahrq.gov/Databases.aspx. The authors did not have special access privileges to the NIS databases. Contact information for further guidance on purchase and download at vog.qrha@rotubirtsiDPUCH.

\section{Competing Interests}

The authors declare that they have no competing interests (financial and non-financial).

\section{Funding}

Dr. Wright receives support as the Anne Gaines and G. Thomas Miller Professor of Medicine through the Johns Hopkins Center for Innovative Medicine.

\section{Acknowledgements}

Not applicable

\section{References}

1. Centers for Disease Control and Prevention. https://www.cdc.gov/visionhealth/basic_information/vision_loss.htm. Accessed July 13, 2020.

2. Rein DB, Zhang P, Wirth KE, et al. The economic burden of major adult visual disorders in the United States. Ophthalmo/2006;124(12):17541760.

3. Press VG, Matthiesen MI, Ranadive A, Hariprasad SM, Meltzer DO, Arora VM. Insights into inpatients with poor vision: A high value proposition. J Hosp Med. 2015 May;10(5):311-3. 
4. Oliver D, Daly F, Martin FC, McMurdo ME. Risk factors and risk assessment tools for falls in hospital in-patients: a systematic review. Age Ageing. 2004;33(2):122-30.

5. Inouye SK, Zhang Y, Jones RN, Kiely DK, Yang F, Marcantonio ER. Risk factors for delirium at discharge: development and validation of a predictive model. Arch Intern Med. 2007;167(13):1406-13.

6. Morse AR, Seiple W, Talwar N, Lee PP, Stein JD. Association of Vision Loss With Hospital Use and Costs Among Older Adults.JAMA Ophthalmol. 2019 Jun 1;137(6):634-640.

7. National Inpatient Sample. https://www.hcup-us.ahrq.gov/nisoverview.jsp. Accessed July 15, 2020.World Health Organization. Blindness and Vision Impairment. https://www.who.int/news-room/fact-sheets/detail/blindness-and-visual-impairment. Accessed November 17, 2020.

8. World Health Organization. Blindness and Vision Impairment. https://www.who.int/news-room/fact-sheets/detail/blindness-and-visualimpairment. Accessed November 17, 2020.

9. Centers for Disease Control and Prevention. Defining Adult Overweight and Obesity. https://www.cdc.gov/obesity/adult/defining.html. Accessed November 17, 2020.

10. Austin SR, Wong YN, Uzzo RG, Beck JR, Egleston BL. (2015). Why Summary Comorbidity Measures Such As the Charlson Comorbidity Index and Elixhauser Score Work. Med Care. 53(9):e65-72.

11. Charlson Comorbidity Index: http://mchp-appserv.cpe.umanitoba.ca/viewConcept.php?printer=Y\&conceptID=1098. Accessed November 17, 2020.

12. Crewe JM, Spilsbury K, Morlet N, Morgan WH, Mukhtar A, Clark A, Semmens JB. Health Service Use and Mortality of the Elderly Blind. 2015 Nov;122(11):2344-50.

13. Choi HG, Lee MJ, Lee SM. Mortality and causes of death in a population with blindness in Korea: A longitudinal follow-up study using a national sample cohort. Sci Rep. 2020 Mar 17;10(1):4891.

14. World Health Organization. Universal Eye Health. A Global Action Plan 2014-2019. https://www.who.int/blindness/AP2014_19_English.pdf. Accessed July 15, 2020.

15. Taheri PA, Butz DA, Greenfield LJ.Length of stay has minimal impact on the cost of hospital admission. J Am Coll Surg. PMID: 10945354.

16. Hirsch R. Length of Stay: Understanding its Shortcomings. 2018 Nov 7. https://www.racmonitor.com/length-of-stay-understanding-itsshortcomings. Accessed July 15, 2020.

17. Lezzoni L. Discharged Blindly. Patient Safety Network 2005. Accessed November 17, 2020.

18. Zizza C, Herring AH, Stevens J, Popkin BM. Length of hospital stays among obese individuals. Am J Public Health 2004; $94: 1587-1591$.

19. Capella-McDonnall ME. The Need for Health Promotion for Adults Who are Visually Impaired. J Vis Impair Blind. March 1, 2007. https://files.eric.ed.gov/fulltext/EJ765539.pdf. Accessed November 22, 2020.

20. Bozkir Ç, Özer A, Pehlivan E.BMJ Open. Prevalence of obesity and affecting factors in physically disabled adults living in the city centre of Malatya. 2016 Sep 8;6(9): e010289.

\section{Tables}




\begin{tabular}{|c|c|c|c|}
\hline & Patients without Blindness & Patients with Blindness & $\mathrm{p}$-value \\
\hline Total & 30,363,917 (99.8) & $37,200(0.2)$ & \\
\hline Age in years, mean $\mathrm{SE}$ & 57.90 .09 & $66.4 \quad 0.24$ & $<0.01$ \\
\hline Female, n (\%) & $17,519,980(57.7)$ & $18,600(50.0)$ & $<0.01$ \\
\hline Race, n (\%) & & & $<0.01$ \\
\hline White & $20,404,552(67.2)$ & $20,832(56.0)$ & \\
\hline Black & 4,615,315 (15.2) & $9,114(24.5)$ & \\
\hline Hispanic & $3,340,030(11.0)$ & $5,022(13.5)$ & \\
\hline Asian or Pacific Islander & $819,825(2.7)$ & $818(2.2)$ & \\
\hline Insurance, n (\%) & & & $<0.01$ \\
\hline Medicare & $14,939,047(49.2)$ & $28,160(75.7)$ & \\
\hline Medicaid & $5,799,508(19.1)$ & $5,056(14.8)$ & \\
\hline Private & $8,350,077$ (27.5) & $3,013(8.1)$ & \\
\hline Uninsured & $1,214,556(4.0)$ & $483(1.3)$ & \\
\hline $\begin{array}{l}\text { Median income (USD), } \\
n(\%)\end{array}$ & & & $<0.01$ \\
\hline$\$ 1-\$ 38,999$ & $9,230,630(30.4)$ & $14,024(37.7)$ & \\
\hline$\$ 39,000-\$ 47,999$ & $8,046,438(26.5)$ & $9,672(26.0)$ & \\
\hline$\$ 48,000-\$ 62,999$ & $7,105,156(23.4)$ & $7,551(20.3)$ & \\
\hline$\$ 63,000$ or more & $5,920,963(19.5)$ & $5,877(15.8)$ & \\
\hline Hospital Bed size, n (\%) & & & 0.14 \\
\hline Small & $6,103,147(20.1)$ & $7,068(19.0)$ & \\
\hline Medium & $8,957,355(29.5)$ & $10,899(29.3)$ & \\
\hline Large & $15,273,050(50.3)$ & $19,158(51.5)$ & \\
\hline Hospital Region, n (\%) & & & $<0.01$ \\
\hline Northeast & $5,678,052(18.7)$ & $5,840(15.7)$ & \\
\hline Midwest & $6,801,517(22.4)$ & $7,886(21.2)$ & \\
\hline South & $11,933,019(39.3)$ & $15,438(41.5)$ & \\
\hline West & $5,890,599$ (19.4) & $7,960(21.4)$ & \\
\hline Teaching hospital, n (\%) & & & 0.17 \\
\hline Non-teaching, $\mathrm{n}(\%)$ & $3,643,670(12.0)$ & $4,203(11.3)$ & \\
\hline Teaching, n (\%) & $26720,247(88.0)$ & $32,996(88.7)$ & \\
\hline
\end{tabular}

*Analyses used Pearson's $\chi^{2}$ test and one-way analysis of variance for categorical and continuous variables respectively. 


\begin{tabular}{lccc}
\hline Co-morbidities & $\begin{array}{c}\text { Patients } \\
\text { without } \\
\text { Blindness } \\
\text { N (\%) }\end{array}$ & $\begin{array}{c}\text { Patients } \\
\text { with } \\
\text { Blindness } \\
\text { N (\%) }\end{array}$ & p-value \\
& & & \\
\hline Total & & & \\
Charlson comorbidity score & & & \\
\hline 0 & $11,902,655(39.2)$ & $5,691(15.3)$ & \\
\hline 1 & $5,860,235(19.3)$ & $5,914(15.9)$ & \\
\hline 2 & $4,099,128(13.5)$ & $5,580(15.0)$ & \\
\hline 3 or more & $8,441,168(27.8)$ & $19,790(53.2)$ & \\
\hline Opioid use & $637,642(2.1)$ & $446(1.2)$ & $<0.01$ \\
\hline Tobacco use & $5,222,593(17.2)$ & $3,720(10.2)$ & $<0.01$ \\
\hline Alcohol use & $1,366,376(4.5)$ & $706(1.9)$ & $<0.01$ \\
\hline Depression & $242,911(0.8)$ & $334(0.9)$ & 0.68 \\
\hline Chronic lung disease & $4,736,771(15.6)$ & $5,914(15.9)$ & $<0.01$ \\
\hline Hypertension & $15,880,328(52.3)$ & $26,226(70.5)$ & $<0.01$ \\
\hline Diabetes with complications & $4,433,131(14.6)$ & $14,619(39.3)$ & $<0.01$ \\
\hline Peripheral vascular disease & $1,457,468(4.8)$ & $3,980(10.7)$ & $<0.01$ \\
\hline & & & \\
\hline
\end{tabular}

‡ble 3. Odd ratios and differences for in-hospital outcomes in patients with and without blindness ages 18 years and older from the National Inpatient Sample (2017)

\begin{tabular}{|c|c|c|c|c|c|c|c|c|}
\hline Outcome & $\begin{array}{l}\text { Patients without } \\
\text { Blindness } \\
\mathrm{N}=30,363,917\end{array}$ & $\begin{array}{c}\text { Patients with } \\
\text { Blindness } \\
\mathrm{N}=37,200\end{array}$ & $\begin{array}{l}\text { Univariate } \\
\text { Odds Ratio }\end{array}$ & $(95 \% \mathrm{CI})$ & P-value & $\begin{array}{l}\text { Multivariate } \\
\text { Odds Ratio }\end{array}$ & $(95 \% \mathrm{CI})$ & P-value \\
\hline -hospital mortality, n (\%) & $668,008(2.2)$ & $1,450(3.9)$ & 1.8 & $(1.6-2.0)$ & $<0.01$ & 1.2 & $(1.0-1.4)$ & 0.01 \\
\hline ischarged to home, n (\%) & $19,250,723(63.4)$ & $14,656(39.4)$ & 0.37 & $(0.35-0.39)$ & $<0.01$ & 0.54 & $(0.51-0.58)$ & $<0.01$ \\
\hline & & & $\begin{array}{c}\text { Univariate } \\
\text { Mean Difference }\end{array}$ & & & $\begin{array}{c}\text { Multivariate } \\
\text { Mean Difference }\end{array}$ & & \\
\hline ean length of stay, days & 4.72 & 6.05 & 1.33 & $(1.18-1.48)$ & $<0.01$ & 0.5 & $(0.3-0.7)$ & $<0.01$ \\
\hline ean charge per case, US dollars & 53,388 & 59,900 & $\$ 6,512$ & $(4,211-8,811)$ & $<0.01$ & $\$ 247$ & $(-2474-2929)$ & 0.85 \\
\hline
\end{tabular}

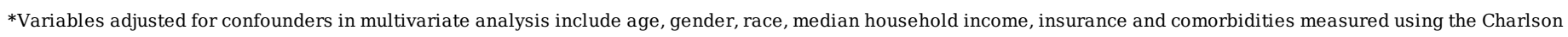
comorbidity index), hospital bed size, teaching status, urban location, and region.

\section{Figures}




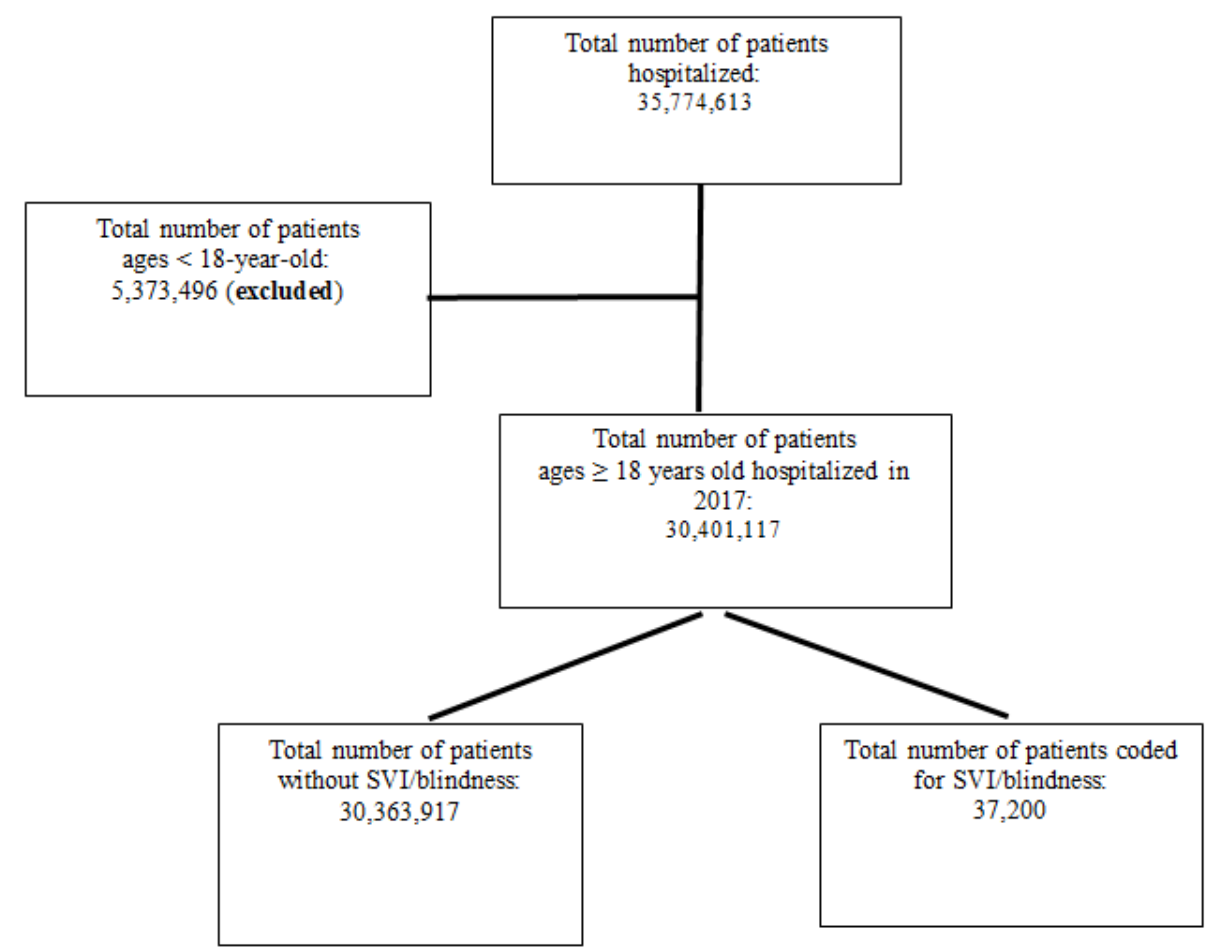

Figure 1

Patient identification flow diagram with data from 2017

\section{Supplementary Files}

This is a list of supplementary files associated with this preprint. Click to download.

- SupplementaryTableA.docx 